\title{
Indonesian Traditional Food Image Identification using \\ Random Forest Classifier based on Color and Texture Features by Siti Mutrofin
}

Submission date: 13-Sep-2020 06:14PM (UTC+0530)

Submission ID: 1385720383

File name: SEIT_2019.pdf (10.27M)

Word count: 4053

Character count: 20648 


\title{
Indonesian Traditional Food Image Identification using Random Forest Classifier based on Color and Texture Features
}

\author{
$1^{\text {st }}$ Yuita Arum Sari, $2^{\text {nd }}$ Fitri Utaminingrum, $3^{\text {rd }}$ Sigit Adinugroho, \\ $4^{\text {th }}$ Ratih Kartika Dewi, $5^{\text {th }}$ Putra Pandu Adikara, $6^{\text {th }}$ Randy Cahya Wihandika \\ Computer Vision Research Group ${ }^{(1,2,3,5,6)}$,Mobile, Game and Multimedia Research Group ${ }^{(4)}$ \\ Faculty of Computer Science, University of Brawijaya \\ Malang, Indonesia \\ yuita@ub.ac.id ${ }^{(1)}, \mathrm{f}_{n}$ ingrum@ub.ac.id(2), sigit.adinu@ub.ac.id ${ }^{(3)}$, \\ ratihkartikad@ub.ac.id ${ }^{(4)}$, adikara.putra@ub.ac.id ${ }^{(5)}$ rendicahya@ub.ac.id ${ }^{(6)}$
}

\author{
$7^{\text {th }}$ Siti Mutrofin \\ Information Systems, Universitas Pesantren Tinggi Darul Ulum \\ Jombang, Indonesia \\ sitimutrofin@ft.unipdu.ac.id
}

\author{
$8^{\text {th }}$ Abidatul Izzah \\ Informatics Engineering, Polytechnic of Malang \\ Kediri, Indonesia \\ abidatul.izzah90@gmail.com
}

\begin{abstract}
Indonesia has various cultures and consequently, it also has huge selection of traditional foods. Since there is new style of people of sharing food images in several social media before eating nowadays, people also have benefit to explore more information, such as recommendation place to eat particular food. When people travel to one place to another place they also have an intention to enjoy the local food, but some of them may not acknowledge the name of traditional food, especially for those who is not a residence in that place. By spreading images to others, it can help other people finding recommended food when visiting the same place. One way to tackle this problem is by identifying food images automatically. In this paper, we propose a new method for recognizing traditional foods in Indonesia. There are $\mathbf{3 8 2}$ images taken using smartphone camera, consisting of 33 classes as training set and 33 images as testing set. All features are extracted using color moments in RGB, LAB, and HSV color spaces and texture feature of Local Binary Pattern (LBP) and Gray Level Co-occurrence Matrix (GLCM). Random Forest Classifier with different number of estimators are used to evaluate the proposed method. The result of combined features consisting of color and texture features reaches $93.5 \%$ of accuracy using $\mathbf{5 0 0}$ estimators. It proves that this method is sufficient to recognize traditional food image.

Index Terms-image classification, color moments, color space,
\end{abstract} LBP, GLCM, Random Forest Classifier

\section{INTRODUCTION}

Social media become favorable and grows rapidly nowadays, so people have a new habit of uploading food photos before enjoying the meals. Sharing information through social media may have important insight for others. Computational process in food image can be adopted to obtain necessary news, such as the recommendation place of choosing certain food [1] or finding recipe of particular food automatically [2].

Food identification is a challenging task, since billion types of foods are available in many shapes, texture, as well as colors. It may occur that one food can be in several versions as well. Thus, it is hard to recognize them based on their shapes, texture or even color separately. Indonesian foods are examples of this complication since single class of traditional food have several shapes. In each area in Indonesia, there are different styles of foods and snacks. They have distinct cultures and it can be recognized by many types of traditional food. When domestic tourists travel to another place in Indonesia, they eager to taste traditional food in that place and spread the information through social media using image captured by smart phone or other cameras. Therefore, Indonesian traditional foods need to be preserved to acknowledge uncommon food for any people who will visit certain place in Indonesia. By widening information through social media using food images, tourists will easily recognize unfamiliar types of food. One of field to develop this system is by using computer vision and machine learning.

Computer vision has successfully applied machine learning to build applications of classifying, identifying, and retrieving similar foods [3]. One of previous research was delivered by [4], which applied SIFT to recognize Indonesian foods image by involving K-Dimmensional Tree (K-D Tree) and backpropagation neural network (BPNN). The accuracy of K-D Tree and BPPN is $51 \%$ and $44 \%$, respectively. SIFT feature considers key points assigned to unique point of image. However, foods have non-rigid images which can have different number of key points for the similar image in a class. It may be affected by lighting environment and point of view when taking a picture. Those differences could produce different key points.

In [5], other features are applied instead of key points, namely color, texture, size and shape. The experimental result 


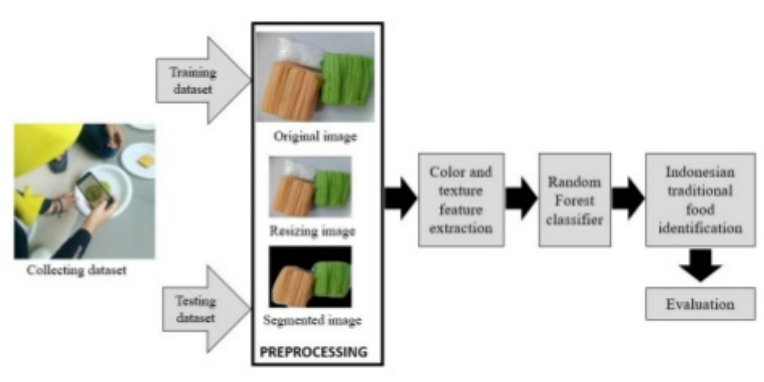

Fig. 1. General phase of proposed method

shows that using support vector machine (SVM) with average cross-validation of $63.76 \%, 76.28 \%, 44.88 \%$, and $45.90 \%$ by using color, texture, size, and shape, respectively. Based on that reason, in this paper we implement color and texture as combined features to deal with defining the characteristics of traditional Indonesian foods which are captured in different lighting environment. For classification method, we employ Random Forest since it surpasses K-Nearest Neighbour and SVM as stated in [6] as classification of 178 fruit images.

In this paper, we conduct a research to identify Indonesian traditional food images using random forest classifier with color and texture features. We ignore shape feature because we do not use proper homogeneous angle and the same type of food images may have different shapes.

\section{Research Methodology}

There are six main steps that are proposed in this paper to recognize traditional Indonesian food images. They are collecting the dataset, preprocessing image, feature extraction using color and texture, constructing random forest classifier, identifying the type of traditional foods, and evaluation. The detail of the phases of the proposed method is depicted in Fig. 1

\section{A. Dataset}

We create our own dataset using 33 categories of traditional Indonesian foods consisting of 382 images. We use several types of snacks and desserts for constructing of traditional Indonesian food images as shown in the Fig. 2. All images were taken using smartphone camera and the food is placed in the center on white-colored plate. The use of white plate is to ease the process of segmentation, whereas the shadow appears due to the uncontrolled lighting indoor environment. Almost all captured food images were taken in perpendicular position.

Taking raw dataset often lead to problems. One of them is imbalance classes in the dataset as shown in Table I where the number of images taken per class are not equal. One class may have very small number of instances, such as 'roti goreng' and 'nagasari' which have 5 images only, while other classes such as 'dadar gulung' has 27 images that is significantly greater than 'roti goreng' and 'nagasari' classes. Therefore, choosing

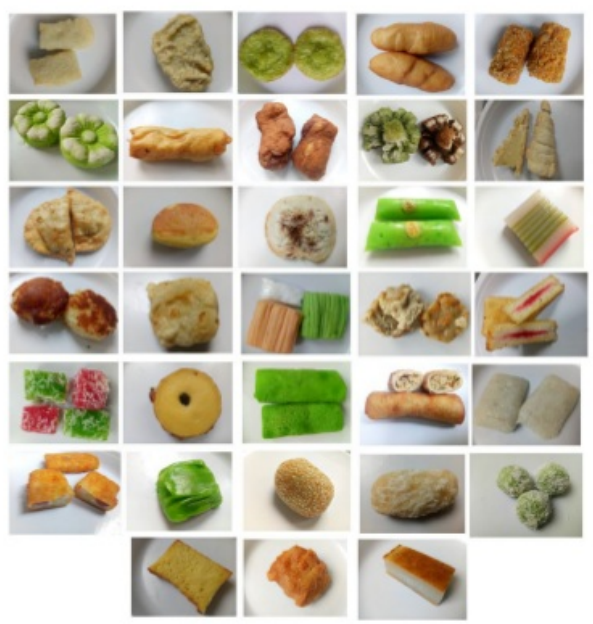

Fig. 2. There are 33 classes of Indonesian traditional food images. From left to right and up to down: jaddah, ubi goreng, cucur, molen pisang, risol bakso, bolu kukus bunga, lumpia ayam, roti goreng, bikang, sus keong, pastel, pukis, surabi, nagasari, lapis, wingko bunder, tape goreng, gethuk lindri, tahu bakso, roti bakar, kue ketela, lumpur, dadar gulung, lumpia rebung, lemper, risol mayo, mendhut, onde-onde, kemplang, klepon, bika ambon, tahu isi, wingko babat

TABLE I

THE NUMBER OF IMAGES IN EACH CLASS

\begin{tabular}{|l|l|l|l|}
\hline Food Names & $\boldsymbol{n}$ & Food Names & $\boldsymbol{n}$ \\
\hline Jaddah & 11 & Gethuk lindri & 10 \\
\hline Ubi goreng & 12 & Tahu bakso & 6 \\
\hline Cucur & 8 & Roti bakar & 16 \\
\hline Molen Pisang & 11 & Kue ketela & 7 \\
\hline Risol Bakso & 20 & Kue Lumpur & 7 \\
\hline bolu kukus bunga & 7 & Dadar gulung & 27 \\
\hline Lumpia ayam & 7 & Lumpia rebung & 8 \\
\hline Roti goreng & 5 & Lemper & 13 \\
\hline Bikang & 7 & Risol mayo & 20 \\
\hline Sus keong & 6 & Mendhut & 8 \\
\hline Pastel & 16 & Onde-onde & 9 \\
\hline Pukis & 8 & Kemplang & 11 \\
\hline Surabi & 6 & Klepon & 18 \\
\hline Nagasari & 5 & Bika Ambon & 24 \\
\hline Lapis & 7 & Tahu isi & 17 \\
\hline Wingko bunder & 12 & Wingko babat & 15 \\
\hline Tape goreng & 18 & & \\
\hline
\end{tabular}

${ }^{*} n$ is number of images

a suitable method of classification is the main important thing to obtain good food identification system as one way to tackle the problem.

\section{B. Preprocessing}

In virtually all machine learning applications, preprocessing is one of the important tasks to do before extracting the features. Preprocessing has an important impact in following process and analysis. As stated in the previous research [7], [8], [9] related to the effect of preprocessing in segmentation can deal with a problem of image clustering especially increasing the evaluation measure. The modification of algorithm 


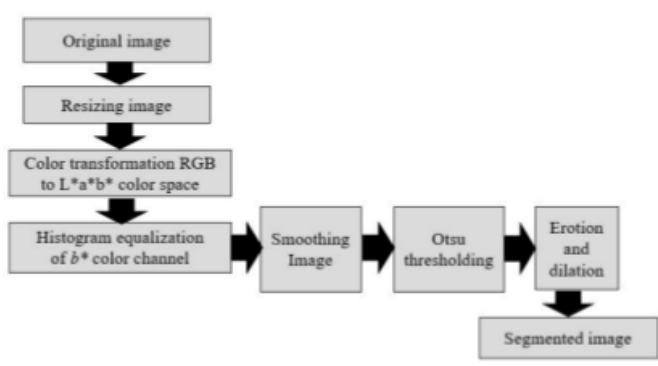

Fig. 3. Preprocessing step

to have better dataset is considered important to enhance the quality of an image [10]. In this paper, we apply several steps of preprocessing which are focused on how to get the main area of foods which is presented in the Fig. 3.

From the original image, resizing image is necessary in order to reduce the complexity during computation. Then, the whole images are transformed into a new color space, that is $L a^{*} b^{*}$. From those three color channels, only $b^{*}$ color channel is used since it represents the main object of food well. To strengthen the area of food, histogram equalization is utilized. After that, double smoothing phase is also applied, consisting of median and Gaussian blurring. The combination can remove noises that introduce difficulties in retrieving the objects. We use the same size of kernels of $55 \times 55$ pixels in smoothing image.

The following steps is for the segmentation. Otsu thresholding is emplyed, which is well tested in this dataset in order to have robust segmentation of images. By using Otsu thresholding, we do not need to set any parameter. The last phase of preprocessing is erosion and dilation to generate specific object more detail rather than smoothing.

\section{Color Feature Extraction}

Color plays an important role in food images recognition since each types of traditional food have different colors. One of method to extract color feature is the color moment. Using the statistic probability, color moments can represent the characteristic of the images. In this paper, we use four kinds of color moment features: mean, standard deviation, skewness and kurtosis.

Mean is the first moment feature which describes the average of intensities value in each color channel of color space. The formula of mean is stated in (1).

$$
\mu=\frac{1}{M N} \sum_{i=1}^{M} \sum_{j=1}^{N} P_{i j}
$$

where $M$ and $N$ are the dimension of the image which is represented with intensities value in each pixel, $P$ is intensity in pixel located in $i$ and $j$.
The second moment feature is standard deviation. This feature is able to understand the disparity of intensities value. The formula of standard deviation explained as follows :

$$
\frac{2}{\sigma}=\sqrt{\frac{1}{M N} \sum_{i=1}^{M} \sum_{j=1}^{N}\left(P_{i j}-\mu\right)^{2}}
$$

The third moment feature is skewness which represents asymmetry size of an image. If an image is symmetry the the value of skewness becomes 0. Skewness is a strong feature to determine the feature in terms of irregular object as food. Skewness' equation is described as (3).

$$
\theta=\frac{\sum_{i=1}^{M} \sum_{j=1}^{N}\left(P_{i j}-\mu\right)^{3}}{M N \sigma^{3}}
$$

The last moment feature that is used in this paper is kurtosis. Kurtosis is used to measure how much color intensity forms a flat or high distribution when compared to a normal distribution. The formula, as described in 3 , is:

$$
\gamma=\frac{\sum_{i=1}^{M} \sum_{j=1}^{N}\left(P_{i j}-\mu\right)^{4}}{M N \sigma^{4}}
$$

\section{Texture Feature Extraction}

Since one class of traditional Indonesian food can have more than one color, other features are required. Local binary pattern (LBP) and gray level co-occurrence matrix (GLCM) are utilized in this research.

1) $L B P$ : LBP is used in grayscale images which can be used for invariant of rotation and lighting condition. LBP is a powerful algorithm for describing texture information of an image. LBP computes certain dimension (for example $8 x 8$ ) and compares it to its neighbour. If the current intensity is greater than neighbor's then it is replaced by 0 ; otherwise is 1 as stated in (5) and (6). Afterwards, computing a histogram is needed for building vector feature of LBP. In this paper, we use 24 number of points with radius $=8$, then 26 bin of histogram is taken.

$$
\operatorname{LBP}\left(x_{c}, y_{c}\right)=\sum_{p=0}^{p-1} s\left(g_{p}-g_{c}\right) 2^{P}
$$

where

$$
s(x)=\left\{\begin{array}{l}
1, x \geq 0 \\
0, x \leq 0
\end{array}\right.
$$

2) GLCM: Gray level co-occurence matrix (GLCM) is a method used for texture analysis and feature extraction. GLCM is a matrix that extract second order statistical texture features [11] [12] and describes the appearance frequency of two pixel pairs with certain intensity in certain distance and direction of the image. The coordinates of pixel pairs have distance and orientation. The distance is represented in pixels and the orientation are represented in angles. Angular orientation is formed based on $0,45,90$ and 135. In this paper, spatial dependence of gray levels calculated with 5 features of co-occurrence matrix with 3 types of distance in which 
$d=1,2,3$. The selection of GLCM features is based on analysis of accuracy to choose the best features suitable for a case. Therefore, $5 \times 4 \times 3=60$ features are created. The 5 features of co-occurrence matrix are listed below:

$$
\text { contrast }=\sum_{i=0}^{l-1} \sum_{j=0}^{l-1} P_{i j}(i-j)^{2}
$$

where $l$ is levels of graylevel

$$
\begin{gathered}
\text { energy }=\sum_{i=0}^{l-1} \sum_{j=0}^{l-1} P_{i j}^{2} \\
\text { homogenity }=\sum_{i=0}^{l-1} \sum_{j=0}^{l-1} \frac{P_{i j}}{1+(i-j))^{2}} \\
\text { correlation }=P_{i j}\left[\frac{\left(i-\mu_{i}\right)\left(j-\mu_{j}\right)}{\sqrt{\left(\sigma_{i}^{2}\right)\left(\sigma_{j}^{2}\right)}}\right] \\
\text { dissimilarity }=\sum_{i=0}^{l-1} \sum_{j=0}^{l-1} P_{i j}|i-j|
\end{gathered}
$$

\section{E. Random Forest Classifier}

Random Forest is one of the supervised machine learning methods. Random forest can be used for regression and classification task. In this case, we use to identify object through classification techniques. Random forest builds several decision trees. Random forest randomly selects a group of training set and combination of features in a tree. One tree is served with decision tree algorithm, then each part of decision tree will produce a prediction. All predictions in all of trees are collected and by using majority voting it can be decided the type of class of certain instance or objects.

The training subset and feature of each decision tree also can overlap, so multiple iteration in each number of tree is needed to give an accurate result. It is also because one tree can provide some noise, so by collecting some of trees are expected to get low evaluation error.

Random forest has been successfully applied in many applications of object identification since it can prevent overfitting [13]. In addition, it can be adopted as well in imbalance number of data in each class as proposed in this paper.

\section{F. Evaluation}

In this paper, we make use of accuracy as performance evaluation of algorithms. Accuracy is simple measurement to give a ratio between correctly predicted class $(t)$ to the total number of images in dataset $(n)$ as shown in 12.

$$
\text { accuracy }=\frac{t}{n}
$$

\section{Results AND Discussion}

There are 33 images in testing set, in which it has 1 image for each class and the rest of 382 images as training set which has different number images per class as explained before in Section A-II. The observation involves understanding the effect of color and/or texture features in recognition in classification, so it has been served as well towards the different number of estimators which is an input for random forest classifier. The result of our system is displayed in Table II. Table II shows that the observation's result for combination between color and texture feature extraction with 500 number of decision tress reach the average value of accuracy is 0.9358 . The misclassified images are 2 images out of 33 images in the testing set. They are: 'kue lumpur' recognized as 'roti bakar selai' and 'tahu isi' recognized as 'onde-onde'. It happens due to the feature extraction. Based on standard deviation of color features, we found that color features have larger variance than texture feature extraction.

In order to analyze the accuracy, the observation compare accuracy based on group of features in certain number of estimators is acquired. Fig. 4 depicts the accuracy in each features. We observed the features from color moment of RGB (12 features), LAB (12 features), and HSV (12 features), while in texture features, there are LBP (26 features) and GLCM (60 features). We also have an experiment to obtain the accuracy from a group of colors ( 36 features) and texture feature (86 features) and the combination of both in which the total of all features (122 features). The number of estimators is set incrementally from 1 to 100 trees. Since the number of features in texture's feature is more than color feature, it affects the result of the low accuracy for some samples, such as 'kue lumpur' and 'tahu isi'.

The impact of color spaces also play necessary role of accuracy's evaluation. LAB shows the best in all number of estimators of random forest classifier over HSV and RGB with an average of accuracy over $70 \%$, while HSV and RGB is $56.87 \%$ and $68.24 \%$, respectively. RGB color space tend to include illumination in each color channel. If the raw image dataset has different lighting condition, using RGB is not proper. Therefore, other color spaces, such as HSV and LAB are used, since both color spaces represent human color perception. Either HSV or LAB each color channel describes lighting component and color component separately.

Apart from color feature, texture feature gives significant effect of accuracy. In this case, as stated in the Fig. 4, LBP generally show better performance over GLCM in different number of estimators. In addition, we observed in color moment feature for each RGB, LAB and HSV color space. From those three color spaces, LAB shows the best result in almost all experiments of number of estimators. However, combined color and texture feature provide remarkable result since it can improve the accuracy of classification performance.

Fig. 5 depicts accuracy in each number of estimators in range of 1 until 100 of trees of combination LAB and texture feature. Overall, the accuracy shows that the more trees are 
TABLE II

THE RESULT OF INDONESIAN FOOD IDENTIFICATION

\begin{tabular}{|c|c|c|c|}
\hline Testing set & True label & Predicted label & Result \\
\hline 䋨 & Gethuk warna warni & Gethuk warna warni & TRUE \\
\hline 4 & Ubi goreng & Ubi goreng & TRUE \\
\hline & Cucur & Cucur & TRUE \\
\hline$\$ 8$ & Molen pisang & Molen pisang & TRUE \\
\hline 96 & Risol bakso & Risol bakso & TRUE \\
\hline & Bolu kukus bunga & Bolu kukus bunga & TRUE \\
\hline whes & Lumpia ayam & Lumpia ayam & TRUE \\
\hline 8 & Bikang & Bikang & TRUE \\
\hline & Sus keong & Sus keong & TRUE \\
\hline a & Pastel & Pastel & TRUE \\
\hline 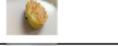 & Pukis & Pukis & TRUE \\
\hline 8. & Surabi & Surabi & TRUE \\
\hline & Nagasari & Nagasari & TRUE \\
\hline & Lapus & Lapus & TRUE \\
\hline & Wingko lingkaran & Wingko lingkaran & TRUE \\
\hline sete & Tape goreng & Tape goreng & TRUE \\
\hline & Gethuk Lindri & Gethuk Lindri & TRUE \\
\hline Q & Tahu bakso & Tahu bakso & TRUE \\
\hline 3 & Roti bakar & Roti bakar & TRUE \\
\hline 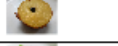 & kue lumpur & Roti bakar selai & FALSE \\
\hline 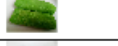 & Dadar gulung & Dadar gulung & TRUE \\
\hline 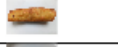 & Lumpia & Lumpia & TRUE \\
\hline & Lemper & Lemper & TRUE \\
\hline & Risol mayo & Risol mayo & TRUE \\
\hline ara & Mendhut & Mendhut & TRUE \\
\hline 8 & Onde-onde & Onde-onde & TRUE \\
\hline 4 & Kemplang & Kemplang & TRUE \\
\hline$\theta$ & Klepon & Klepon & TRUE \\
\hline & Bika Ambon & Bika Ambon & TRUE \\
\hline 율 & Tahu isi & Onde-onde & FALSE \\
\hline 봉 & Wingko kotak & Wingko kotak & TRUE \\
\hline
\end{tabular}

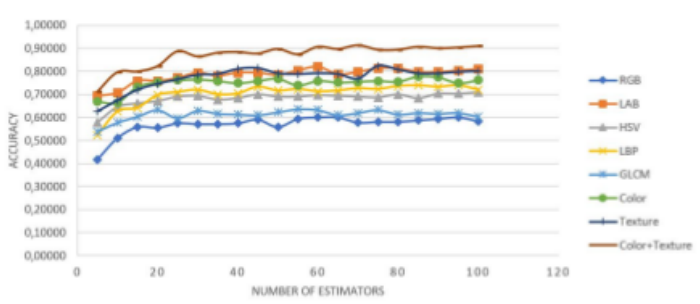

Fig. 4. Accuracy in Different Features

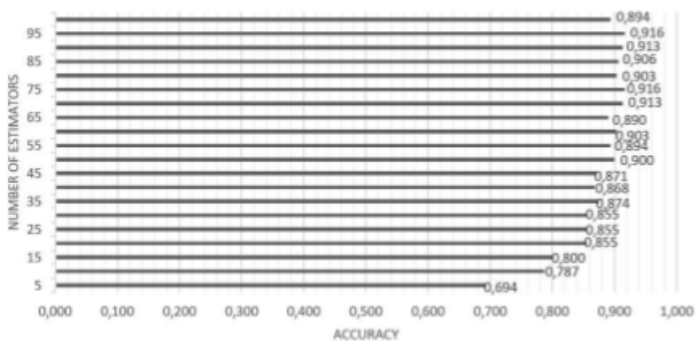

Fig. 5. Combination of LAB and Texture Feature

created the higher accuracy result of classification. The number of estimators greater than 15 trees produce 0.8 accuracy in average. Because adding the number of tress can increase the accuracy, then in III we observed until 500 number of estimators in each group of feature. It shows that combination of both color and texture remains to have the best accuracy rather than single group of feature which reaches more than 0.9 of accuracy. Among all groups of color features, LAB is the best color space to be applied in this research since lighting condition when capturing image is not adjusted. It has slightly different accuracy to combination all color features and texture feature. Based on the result and analysis, combination of color and texture feature is reliable for classification using random forest.

TABLE III

THE NUMBER OF ESTIMATORS

\begin{tabular}{|l|l|l|l|l|l|}
\cline { 2 - 6 } \multicolumn{1}{c|}{} & \multicolumn{7}{l}{ number of estimators } \\
\hline Feature extraction & $\mathbf{1 0 0}$ & $\mathbf{2 0 0}$ & $\mathbf{3 0 0}$ & $\mathbf{4 0 0}$ & $\mathbf{5 0 0}$ \\
\hline RGB & 0,597 & 0,600 & 0,600 & 0,623 & 0,590 \\
\hline LAB & 0,800 & 0,810 & 0,819 & 0,826 & 0,826 \\
\hline HSV & 0,687 & 0,684 & 0,690 & 0,687 & 0,681 \\
\hline LBP & 0,748 & 0,752 & 0,742 & 0,765 & 0,758 \\
\hline GLCM & 0,613 & 0,616 & 0,613 & 0,629 & 0,610 \\
\hline Color & 0,752 & 0,748 & 0,765 & 0,761 & 0,758 \\
\hline Texture & 0,790 & 0,810 & 0,800 & 0,790 & 0,806 \\
\hline Color+Texture & $\mathbf{0 , 9 2 3}$ & $\mathbf{0 , 9 2 3}$ & $\mathbf{0 , 9 2 9}$ & $\mathbf{0 , 9 2 6}$ & $\mathbf{0 , 9 3 5}$ \\
\hline LAB+Texture & $\mathbf{0 , 9 1 6}$ & $\mathbf{0 , 9 2 9}$ & $\mathbf{0 , 9 1 9}$ & $\mathbf{0 , 9 2 6}$ & $\mathbf{0 , 9 2 6}$ \\
\hline & \multicolumn{7}{|l}{} \\
\hline
\end{tabular}




\section{CONCLUSION}

A new phase of handling classification of Indonesian traditional food using Random Forest based on color and feature extraction has been proposed. Random Forest shows good result when building more number of estimators. From all experiments the higher number of estimators increases accuracy in almost all groups of feature. In color space feature extraction using color moment, LAB shows the best result in whole experiment of number estimators, while LBP texture is better than GLCM to identify Indonesian traditional food image. However, the combination of both color and texture can boost the accuracy over than $90 \%$ when the number of estimators is raised.

For further research the improvement of segmentation is utilized since it affects the process of feature extraction. Applying color correction is also considered to reduce segmentation miss due to shadow. We also consider for applying the recognition system for several foods in a plate.

\section{ACKNOWLEDGMENT}

The author would like to say thank you to Faculty of Computer Science, University of Brawijaya for supporting us by giving fully funded program in this research. We also thank all students who are involved in the food research project.

\section{REFERENCES}

[1] Bolaos M, Valdivia M, Radeva P. Where and What Am I Eating? ImageBased Food Menu Recognition. InEuropean Conference on Computer Vision 2018 Sep 8 (pp. 590-605). Springer, Cham.

[2] Wang X, Kumar D, Thome N, Cord M, Precioso F. Recipe recognition with large multimodal food dataset. In 2015 IEEE Intemational Conference on Multimedia \& Expo Workshops (ICMEW) 2015 Jun 29 (pp. 1-6). IEEE.

[3] Sahoo D, Hao W, Ke S, Xiongwei W, Le H, Achananuparp P, Lim EP, Hoi SC. FoodAI: Food Image Recognition via Deep Leaming for Smart Food Logging. 2019.

[4] Giovany S, Putra A, Hariawan AS, Wulandhari LA. Machine learning and sift approach for Indonesian food image recognition. Procedia computer science. 2017 Jan 1;116:612-20.

[5] Pouladzadeh P, Shimohammadi S, Al-Maghrabi R. Measuring calorie and nutrition from food image. IEEE Transactions on Instrumentation and Measurement. 2014 Aug;63(8):1947-56.

[6] Najeeb T, Safar M. Dates Maturity Status and Classification Using Image Processing. In 2018 International Conference on Computing Sciences and Engineering (ICCSE) 2018 Mar 11 (pp. 1-6). IEEE.

[7] Sari YA, Adinugroho S. Tomato ripeness clustering using 6-means algorithm based on v-channel otsu segmentation. In 2017 5th International Symposium on Computational and Business Intelligence (ISCBI) 2017 Aug 11 (pp. 32-36). IEEE.

[8] Sari YA, Adinugroho S, Ginardi RH, Suciati N. Enhancing tomato clustering evaluation using color correction with improved linear regression in preprocessing phase. In2016 Intemational Conference on Advanced Computer Science and Information Systems (ICACSIS) 2016 Oct 15 (pp. 401-406). IEEE.

[9] Sari YA, Adinugroho S. Preprocessing of tomato images captured by smartphone cameras using color correction and V-channel Otsu segmentation for tomato maturity clustering. In 2018 5th International Conference on Electrical and Electronic Engineering (ICEEE) 2018 May 3 (pp. 399-403). IEEE.

[10] Sari YA, Ginardi RH, Suciati N. Color correction using improved linear regression algorithm. International Conference on Information and Communication Technology and Systems (ICTS) 2015 Sep 16 (pp. 73 78). IEEE.
[11] Shabanzade, Maliheh, MortezaZahedi, and Seyyed Amin Aghvami. "Combination of local descriptors and global features for leaf recognition." Signal and Image Processing: An Intemational Journal (SIPIJ). v2 i3 (2011): 23-31

[12] Albregtsen, Fritz. "Statistical texture measures computed from gray level coocurrence matrices." Image Processing Laboratory, Department of Informatics, University of Oslo :1-14 (2015).

[13] Li HB, Wang W, Ding HW, Dong J. Trees weighting random forest method for classifying high-dimensional noisy data. In2010 IEEE 7th Intemational Conference on E-Business Engineering 2010 Nov 10 (pp. 160-163). IEEE.

[14] Gallo G, Torrisi A. Random forests based WCE frames classification. In2012 25th IEEE Intemational Symposium on Computer-Based Medical Systems (CBMS) 2012 Jun 20 (pp. 1-6). IEEE.

[15] Mahapatra D. Analyzing training information from random forests for improved image segmentation. IEEE Transactions on Image Processing. 2014 Apr,23(4):1504-12. 
Indonesian Traditional Food Image Identification using Random Forest Classifier based on Color and Texture Features

ORIGINALITY REPORT

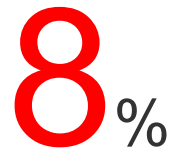

SIMILARITY INDEX
$1 \%$

INTERNET SOURCES
$5 \%$

PUBLICATIONS
$3 \%$

STUDENT PAPERS

\section{PRIMARY SOURCES}

1

Submitted to New University of Astana

Student Paper

2 Submitted to Siddaganga Institute of Technology

Student Paper

3

Yuita Arum Sari, Sigit Adinugroho, Putra Pandu Adikara, Abidatul Izzah. "Multiplication of $\mathrm{V}$ and

$\mathrm{Cb}$ color channel using Otsu thresholding for tomato maturity clustering", 2017 International

Conference on Sustainable Information

Engineering and Technology (SIET), 2017 Publication

Ahmad Fauzi Ahsani, Yuita Arum Sari, Putra

Pandu Adikara. "Food Image Retrieval with

Gray Level Co-Occurrence Matrix Texture

Feature and CIE L*a*b* Color Moments

Feature", 2019 International Conference on

Sustainable Information Engineering and

Technology (SIET), 2019

Publication 
6 Stanley Giovany, Andre Putra, Agus S

Hariawan, Lili A Wulandhari. "Machine Learning

and SIFT Approach for Indonesian Food Image

Recognition", Procedia Computer Science, 2017

Publication

7

I Gede. "Texture Analysis on Image Motif of

Endek Bali using K-Nearest Neighbor

Classification Method", International Journal of

Advanced Computer Science and Applications,

2015

Publication

8 Yuita Arum Sari, Sigit Adinugroho. "Tomato ripeness clustering using 6-means algorithm based on v-channel otsu segmentation", 2017 5th International Symposium on Computational and Business Intelligence (ISCBI), 2017

Publication

9 Submitted to Universitas Brawijaya Student Paper

10 Submitted to Multimedia University Student Paper

Submitted to University of Strathclyde 
Siti Mutrofin, Abdul Muiz Khalimi, Eddy

Kurniawan, Raden Venantius Hari Ginardi,

Chastine Fatichah, Yuita Arum Sari. "Detection

of Potentially Students Drop Out of College in

Case of Missing Value Using C4.5", 2019

International Conference on Sustainable

Engineering and Creative Computing (ICSECC),

2019

Publication

13

Yuita Arum Sari, Sigit Adinugroho.

"Preprocessing of tomato images captured by

smartphone cameras using color correction and

V-channel Otsu segmentation for tomato

maturity clustering", 2018 5th International

Conference on Electrical and Electronic

Engineering (ICEEE), 2018

Publication

14

Abidatul Izzah, Yuita Arum Sari, Ratna

Widyastuti, Toga Aldila Cinderatama. "Mobile

app for stock prediction using Improved Multiple

Linear Regression", 2017 International

Conference on Sustainable Information

Engineering and Technology (SIET), 2017

Publication

15 www.idrbt.ac.in

Internet Source

$<1 \%$

"MultiMedia Modeling", Springer Science and 
16 Business Media LLC, 2017

17 Yuita Arum Sari, Ratih Kartika Dewi, Jaya

Mahar Maligan, Anindya Sasri Ananta, Sigit

Adinugroho. "Automatic Food Leftover

Estimation in Tray Box Using Image

Segmentation", 2019 International Conference

on Sustainable Information Engineering and

Technology (SIET), 2019

Publication

18 Dewi, Ratih Kartika, and R. V. Hari Ginardi.

"Feature extraction for identification of

sugarcane rust disease", Proceedings of

International Conference on Information

Communication Technology and System (ICTS)

2014, 2014.

Publication

19

"Computer Vision - ECCV 2018 Workshops",

Springer Science and Business Media LLC,

2019

Publication

20 spie.org

Internet Source

21 Fitri Utaminingrum, M Ali Fauzi, Randy Cahya Wihandika, Sigit Adinugroho et al.

"Development of computer vision based obstacle detection and human tracking on smart 
wheelchair for disabled patient", 2017 5th International Symposium on Computational and Business Intelligence (ISCBI), 2017

Publication

Exclude quotes

Off

Exclude matches

Off

Exclude bibliography

On 


\section{Indonesian Traditional Food Image Identification using Random Forest Classifier based on Color and Texture Features}

GRADEMARK REPORT

FINAL GRADE

10

PAGE 1

PAGE 2

PAGE 3

PAGE 4

PAGE 5

PAGE 6
GENERAL COMMENTS

Instructor 